\title{
Phloretin induces apoptosis of non-small cell lung carcinoma A549 cells via JNK1/2 and p38 MAPK pathways
}

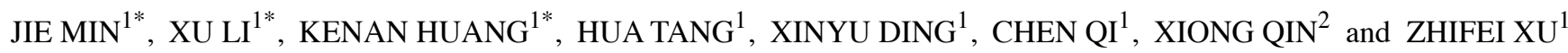 \\ ${ }^{1}$ Department of Thoracic and Cardiovascular Surgery, Changzheng Hospital, The Second Military Medical University, \\ Shanghai 200003; ${ }^{2}$ Department of Thoracic and Cardiovascular Surgery, First People's \\ Hospital of Shanghai, Shanghai Jiaotong University, Shanghai, P.R. China
}

Received July 10, 2015; Accepted August 21, 2015

DOI: $10.3892 /$ or.2015.4325

\begin{abstract}
Phloretin ( $\mathrm{Ph})$ existing in apples, pears and various vegetables is known to have antitumor activities in several cancer cell lines. However, little is known about its effect on human lung cancer cells. The aim of the present study was to see whether Ph could induce apoptosis of non-small cell lung cancer (NSCLC) cells, and explore the possible underlying mechanism of action. We found that $\mathrm{Ph}$ markedly induced cell apoptosis of NSCLC cell line A549, and inhibited the migration of A549 cells in a dose-dependent manner. The expression level of BAX, cleaved caspase- 3 and -9 , and degraded form of PARP was increased and Bcl-2 was decreased after $\mathrm{Ph}$ treatment. In addition, the phosphorylation of P38 MAPK, ERK1/2 and JNK1/2 was increased in a dose-dependent manner in parallel with $\mathrm{Ph}$ treatment. Inhibition of P38 MAPK and JNK1/2 by specific inhibitors significantly abolished the Ph-induced activation of the caspase- 3 and -9 . In vivo tumor-suppression assay further indicated that $\mathrm{Ph}(20 \mathrm{mg} / \mathrm{kg})$ displayed a more significant inhibitory effect on A549 xenografts in tumor growth. All these findings indicate that $\mathrm{Ph}$ is able to inhibit NSCLC A549 cell growth by inducing apoptosis through P38 MAPK and JNK1/2 pathways, and therefore may prove to be an adjuvant to the treatment of NSCLC.
\end{abstract}

Correspondence to: Dr Zhifei Xu, Department of Thoracic and Cardiovascular Surgery, Changzheng Hospital, The Second Military Medical University, 415 Fengyang Road, Shanghai 200003, P.R. China E-mail: doctorxzf@163.com

Dr Xiong Qin, Department of Thoracic and Cardiovascular Surgery, First People's Hospital of Shanghai, Shanghai Jiaotong University, Shanghai, P.R. China

E-mail: qinxiong2014@163.com

*Contributed equally

Key words: phloretin, apoptosis, P38 MAPK, lung cancer, migration

\section{Introduction}

Lung cancer is a major cause of morbidity and mortality worldwide and the most common cause of cancer-related death (1). Non-small cell lung cancer (NSCLC) accounts for $\sim 85 \%$ of all lung cancers. Although surgical and chemotherapeutic treatments have made great contributions in lung cancer, these methods may induce serious long-term adverse effects. Various natural herbal products have gained increasing attention due to their potential anticancer effects against NSCLC $(2,3)$.

Phloretin (Ph) (2',4',6'-trihydroxy-3-(4-hydroxyphenyl)propiophenone) is a natural polyphenolic compound existing in apples, pears and other plants of the rosaceae family and has been found to have anti-inflammatory and immunosuppressive effects on both lymphoid- and myeloid-derived cell lines (4). Ph has also been shown to have antitumor activities by inducing apoptosis in human leukemia cells, bladder cancer and human colon cancer cells (5-7), and inhibiting the growth, invasiveness and migration of human liver cancer cells (8). However, little is known about its effects on human lung cancer cells.

In the present study, we investigated the possible anticancer effects of $\mathrm{Ph}$ on A549 lung adenocarcinoma cells in vitro and in vivo, and discussed the underlying molecular mechanisms. We demonstrated that Ph could inhibit A549 cell proliferation by inducing apoptosis, and that upregulation of JNK, ERK, Bax and P38 MAPK by Ph was associated with the downregulation of $\mathrm{Bcl}-2$ and $\mathrm{NF}-\mathrm{\kappa B}$, and the activation of caspase-3 and -9 , and P53, suggesting that Ph may be a useful plant product for the treatment of lung cancer.

\section{Materials and methods}

Chemicals and reagents. $\mathrm{Ph}, 3-(4,5-$ dimethylthiazol2-yl)-2,5-diphenyltetrazolium bromide (MTT) and dimethylsulfoxide (DMSO) were purchased from Sigma Chemical Co. Dulbecco's modified Eagle's medium (DMEM) and fetal bovine serum (FBS) were obtained from Life Technologies. FITC-Annexin V/PI apoptosis detection kit was purchased from BD Biosciences. Ph stock solution was prepared into 50, 100 and $200 \mu \mathrm{M}$ concentrations in DMSO and stored at $-20^{\circ} \mathrm{C}$. The final concentration of DMSO for all treatments was consistently $<0.1 \%$. Specific inhibitors for 
JNK1/2 (SP600125), ERK1/2 (U0126) or P38 (SB202190) were purchased from Calbiochem. The following antibodies were used: JNK1, p-JNK1/2 (Cell Signaling), P53, cleaved caspase-3, caspase-9, NF- $\kappa$ B, MMP-9 (Santa Cruz), P38, p-P38, ERK1/2, p-ERK1/2, Bcl-2, Bax and PARP (Bioworld Technology), and GAPDH (Sigma).

Cell culture. Human NSCLC A549, H1299 and bronchial epithelial cells (Beas-2b) were from the Institute of Biochemistry and Cell Biology (Shanghai Institutes for Biological Sciences, CAS). Cells were maintained in DMEM supplemented with $10 \%$ FBS in a humidified incubator under $5 \% \mathrm{CO}_{2}$ at $37^{\circ} \mathrm{C}$.

In vitro cytotoxicity assay. MTT was performed as previously described (9). Cells were cultured into a 96-well plate (1x $10^{4} /$ well), stimulated with different concentrations $(0,25$, 50,100 and $200 \mu \mathrm{M}$ ) of $\mathrm{Ph}$ in culture medium when the cells were $80-90 \%$ confluent. After $48 \mathrm{~h}$ Ph of stimulation, the medium was removed and $100 \mu \mathrm{l}$ MTT was added to each well $(0.5 \mathrm{mg} / \mathrm{ml}$ final concentration) for further incubation for $4 \mathrm{~h}$. Then the medium was removed, and $100 \mu 1$ DMSO was added to dissolve the solid formazan for $15 \mathrm{~min}$. The absorbance of each well was read at $570 \mathrm{~nm}$ using a microplate reader (Thermo Fisher).

Fluorescence observation of cell death. A549 cells (6x10 cells/well) on 96-well plates were incubated with phosphatebuffered saline (PBS) control and $\mathrm{Ph}(50,100$ and $200 \mu \mathrm{M})$ for $24 \mathrm{~h}$, then treated with Hoechst $33342(10 \mathrm{mg} / \mathrm{ml})$ for another $1 \mathrm{~h}$, stained with propidium iodide (PI; $100 \mathrm{mg} / \mathrm{ml}$ ) for $15 \mathrm{~min}$ (10), washed with PBS three times and observed on Operetta high content analysis system (Perkin-Elmer).

Annexin V/PI double staining. To detect apoptosis in A549 cells after exposure to $\mathrm{Ph}$, the FITC-Annexin $\mathrm{V}$ apoptosis detection kit was used to quantify the number of cells in different stages of cell death. Briefly, A549 cells seeded into 6-well plates, and treated with PBS control and $\mathrm{Ph}(50,100$ and $200 \mu \mathrm{M})$ for $48 \mathrm{~h}$. Then, $1 \times 10^{5}$ cells were re-suspended in $100 \mu \mathrm{l} 1 \mathrm{X}$ binding buffer. After addition of FITC-Annexin V and PI (5 $\mu \mathrm{l}$ each), the cell suspension was gently vortexed and incubated for $20 \mathrm{~min}$ at room temperature in the dark. After addition of $400 \mu 11 \mathrm{X}$ binding buffer to each tube, cells were analyzed by flow cytometry (BD Calibur).

Cell cycle analysis. To determine the effect of $\mathrm{Ph}$ on the cell cycle, A549 cells were seeded into 6-well plates, treated with PBS control and $\mathrm{Ph}(50,100$ and $200 \mu \mathrm{M})$ for $48 \mathrm{~h}$, fixed with $70 \%$ ethanol at $4^{\circ} \mathrm{C}$ for $30 \mathrm{~min}$, and then incubated for another $30 \mathrm{~min}$ in the dark, at room temperature with PI buffer [50 mg/ml containing ribonuclease A $(50 \mathrm{ng} / \mathrm{ml})]$. Cell cycle distribution was analyzed for 10,000 collected cells with Aria II flow cytometer (BD Biosciences).

Transwell migration assay. The effect of $\mathrm{Ph}$ on migration of A549 cells was further analyzed using Transwell chambers with 8-mm porous membrane (Corning, Corning, NY, USA). Cells were treated with PBS control and different concentrations $(10,20$ and $40 \mu \mathrm{M})$ of $\mathrm{Ph}$ for $24 \mathrm{~h}$, and then loaded into the migration chamber at $1 \times 10^{5}$. Medium containing $10 \%$ FBS was placed in the lower chambers. After allowing cell migration for $6 \mathrm{~h}$, cells were removed from the upper side of the membrane; migratory cells on the lower side of the membrane were fixed with $4 \%$ paraformaldehyde for $20 \mathrm{~min}$, and then washed with PBS three times before being stained with crystal violet for another $10 \mathrm{~min}$ (11). The number of migratory cells was counted by fluorescence microscopy (magnification, x100).

Western blotting. A549 cells were seeded into 6-well plates and incubated with PBS control and different concentrations $(50,100$ and $200 \mu \mathrm{M})$ of $\mathrm{Ph}$ for $48 \mathrm{~h}$, lysed in RIPA buffer (50 mM Tris- $\mathrm{HCl}, \mathrm{pH} 7.2,150 \mathrm{mM} \mathrm{NaCl}, 1 \% \mathrm{NP} 40,0.1 \%$ SDS, 0.5\% DOC, $1 \mathrm{mM}$ PMSF, $25 \mathrm{mM} \mathrm{MgCl}$, supplemented with a phosphatase inhibitor cocktail) and finally subjected to immunoblotting analysis with indicated antibodies. GAPDH were diluted to 1:2,000, P53, cleaved caspase-3 and -9, NF- $\mathrm{kB}$, MMP-9 were diluted to 1:200; and JNK1, p-JNK1/2, P38, p-P38, ERK1/2, p-ERK1/2, Bcl-2, Bax and PARP were diluted to $1: 1,000$.

In vivo antitumor effect. Female nude mice (BK Biotech) aged 5 weeks were used. A549 cells $\left(5 \times 10^{6}\right)$ were suspended in Matrigel (BD Biosciences) and injected subcutaneously (s.c.) into the mice. All animal procedures were performed following the protocol approved by the Institutional Animal Care Committee of Shanghai Institute of Biochemistry and Cell Biology (Shanghai, China). Mice bearing evident tumors were randomly divided into PBS control group, low-dose (10 mg/kg) Ph group, and high-dose (20 mg/kg) Ph group. $\mathrm{Ph}$ was dissolved in PBS for intraperitoneal (i.p.) administration to the mice every two days for three weeks. Animals were euthanized with carbon dioxide. Tumor masses were isolated and tumor weight was measured as previously described (12).

Statistical analysis. Results are expressed as mean \pm SD (range) or percentage. The difference between two groups was analyzed using the Student's t-test. Statistical analyses were performed using the one-way analysis of variance (ANOVA) followed by Tukey's post hoc test when more than three groups were analyzed. A P-value $<0.05$ was considered to indicate a statistically significant result. The differentiation of amount of protein expressions were calculated using Image Lab version 4.0 software (Bio-Rad Laboratories, Inc.). All calculations were performed using GraphPad Prism software (GraphPad Software, San Diego, CA, USA).

\section{Results}

Cytotoxic effects of Ph-treated A549 and H1299 cells. The chemical structure of $\mathrm{Ph}$ is shown in Fig. 1A (13). The cytotoxicity comparison of Ph on A549, H1299 and Beas-2b cells was evaluated. After cells were treated with different concentrations $(0,25,50,100$ and $200 \mu \mathrm{M})$ of $\mathrm{Ph}$ for $48 \mathrm{~h}, \mathrm{Ph}$ exhibited a moderate effect on normal human Beas- $2 \mathrm{~b}$ cells, and $\mathrm{Ph}$ had more cytotoxic effects on A549 than H1299 cells (Fig. 1B). Furthermore, A549 cancer cells were dose- and time-dependently observed when the cells were treated with Ph for 6, 24, 36 and $48 \mathrm{~h}$ (Fig. 1C). 
<smiles>O=C(CCc1ccc(O)cc1)c1c(O)cc(O)cc1O</smiles>
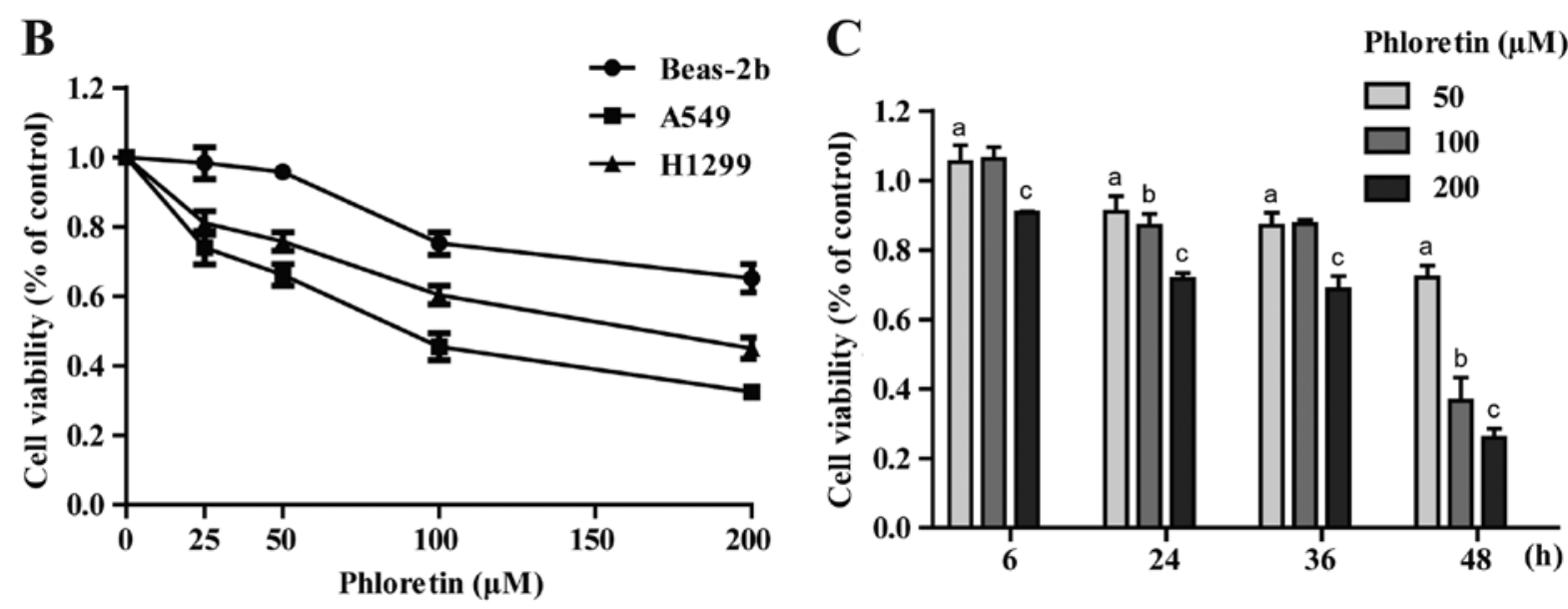

Figure 1. Cytotoxic effect of Ph on Beas-2b, A549 and H1299 cells. (A) Structure of Ph. (B) Viability analysis of Beas-2b, A549 and H1299 cells incubated in the indicated concentrations of $\mathrm{Ph}$ for $48 \mathrm{~h}$, as assayed by MTT as described in the Materials and methods. (C) Viability of A549 cells incubated in 50,100 and $200 \mu \mathrm{M}$ of concentrations of $\mathrm{Ph}$ for $6,24,36$ and $48 \mathrm{~h}$. Each bar represents the mean $\pm \mathrm{SD}, \mathrm{n}=3$. Bars with different letters are significantly different at $\mathrm{P}<0.05$ at each time point.

Ph-induced cell death in A549 cells. To further compare the cytotoxicity between different concentrations of $\mathrm{Ph}$ on A549 cells, cell death assay was performed on Operetta high content analysis system. A549 cells were incubated with PBS control and different concentrations $(50,100$ and $200 \mu \mathrm{M})$ of $\mathrm{Ph}$ for $24 \mathrm{~h}$, and then double stained with Hoechst 33342 (blue indicates the nucleus) and PI (red indicates dead cells). As shown in Fig. 2, Ph significantly increased the cell death rate in a dose-dependent manner, and A549 cells became more curved and thinner with the concentration of $\mathrm{Ph}$ increasing.

Ph-induced cell apoptosis in A549 cells. To determine whether the inhibitory effect of $\mathrm{Ph}$ on cell viability was associated with the induction of cell apoptosis, A549 cells were treated with different concentrations $(0,50,100$ and $200 \mu \mathrm{M})$ of Ph for $24 \mathrm{~h}$. As shown in Fig. 3A, in PBS control group, the percentage of cells in the sub-G1 fraction was low $(0.43 \%)$, and a significant proportion of cells $(20.45 \%)$ went into sub-G1 phase when treated with Ph at $200 \mu \mathrm{M}$. Apoptotic cells with a lower DNA content should fall into similar sub-G1 region in cell cycle on flow cytometric analysis (10). Cell cycle analysis by flow cytometry showed a dose-dependent increased accumulation of cell population in sub-G1 phase. Annexin V and PI double staining displayed an increased percentage of apoptotic cells and dead cells after Ph treatment for $24 \mathrm{~h}$ (Fig. 3B and C). These results suggest that the strong effect of $\mathrm{Ph}$ on A549 cells may be due to induction of more apoptosis with the increased concentration.

Effect of Ph on A549 cell migration. The potential function of $\mathrm{Ph}$ on A549 tumor cell migration was characterized by Transwell migration assay. Cells were treated with indicated concentrations of $\mathrm{Ph}$ for $24 \mathrm{~h}$, and loaded into the migration chamber at $1 \times 10^{5}$. The results showed that $\mathrm{Ph}$ treatment slowed down the migration of A549 cells in a concentration-dependent manner. As shown in Fig. 4, $40 \mu \mathrm{M} \mathrm{Ph}$ markedly inhibited the migration of A549 cells.

Ph induces activation of caspase-3 and -9 in A549 cells. To further investigate whether caspase activation was involved in $\mathrm{Ph}$-induced apoptosis, activation of caspase-3 and -9 and PARP was detected. As shown in Fig. 5A, exposure of A549 cells to $\mathrm{Ph}(0,50,100$ and $200 \mu \mathrm{M})$ for $24 \mathrm{~h}$ increased the number of cleaved fragments of caspase- 3 and -9 in a dose-dependent manner. It is known that PARP is a characteristic marker of apoptosis (14), the abundance of the cleaved form of PARP was increased compared to the control. Ph treatment at $200 \mu \mathrm{M}$ for $24 \mathrm{~h}$ increased the expression level of cleaved caspase- 3 and -9 and cleavage form of PARP by 2.6-, 1.3- and 1.5-fold compared to the control, respectively. $\mathrm{Ph}$ decreased $\mathrm{Bcl}-2$ and NF- $\mathrm{KB}$, and increased the expression level of P53 and Bax in a dose-dependent manner. As shown in Fig. 5B, compared to the control, $\mathrm{Ph}$ treatment at $200 \mu \mathrm{M}$ for $24 \mathrm{~h}$ significantly increased the expression level of P53 and Bax by 1.8 - and 2.3 -fold, respectively, and decreased the expres-

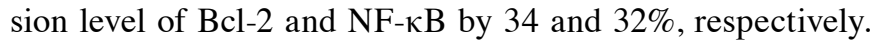
These data suggest that caspase-3, and -9, PARP, Bcl-2, Bax, $\mathrm{NF}-\kappa \mathrm{B}$ and P53 were involved in Ph-induced apoptosis. MMPs can degrade the basement membrane and play main roles in promotion of cancer invasion and metastasis (15). As anticipated, we also found that the expression level of MMP-9 was decreased in Ph-treated A549 cells by $22 \%$, which is consistent with previous data from the migration assay (Fig. 4A).

Ph-induced apoptosis is involved in the regulation of P38 MAPK and JNK signaling pathways in A549 cells. MAPK signaling pathway plays an important role in the action of chemotherapeutic drugs in the regulation of apoptosis (16-18). 


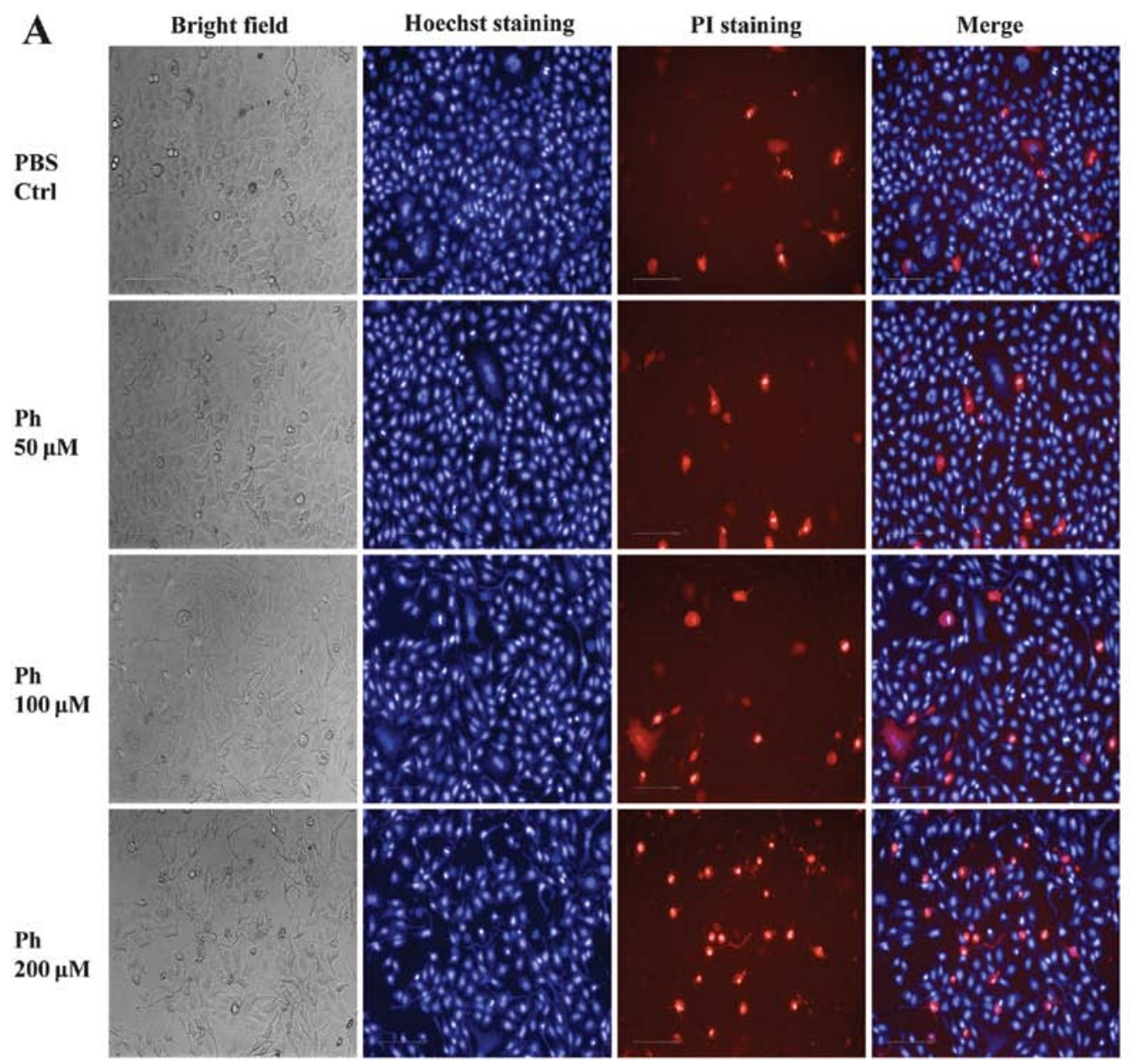

B

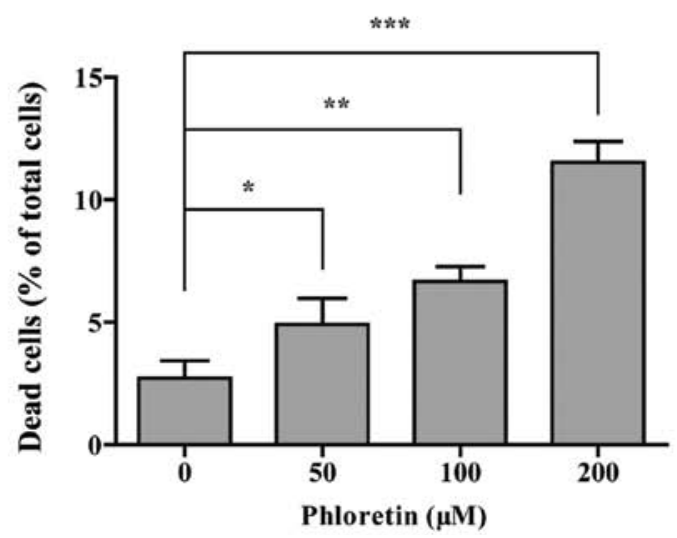

Figure 2. Ph-elicited concentration-dependent A549 cell death as visualized with a fluorescence microscope. Representative Hoechst 33342, propidium iodide (PI) staining of A549 cells indicated concentrations of Ph for $24 \mathrm{~h}$. Scale bar equals $100 \mathrm{~mm}$. (B) Dead cell counting against the total A549 cells treated with indicated concentrations of $\mathrm{Ph}$ for $24 \mathrm{~h}$. Data are shown with mean $\pm \mathrm{SD}$ of three separate experiments; ${ }^{*} \mathrm{P}<0.05,{ }^{* * *} \mathrm{P}<0.005,{ }^{* * * *} \mathrm{P}<0.001$.

To see whether MAPKs were involved in Ph-induced apoptosis, we first examined the activation status of JNK,ERK and P38 by western blotting with antibodies specific to the phosphorylated forms of these kinases. As shown in Fig. 6, treatment of cells with $(0,50,100$ and $200 \mu \mathrm{M}) \mathrm{Ph}$ increased the phosphorylated form of JNK, ERK and P38 in a dose-dependent manner, with the total protein levels remaining steady, indicating the activation of JNK, ERK and P38 in A549 cells. In contrast, A549 cells were pretreated with $25 \mu \mathrm{M}$ SP600125 (a JNK inhibitor), U0126 (an ERK inhibitor) or SB202190 (a P38 inhibitor) for $45 \mathrm{~min}$, treated with $200 \mu \mathrm{M} \mathrm{Ph}$ for another $24 \mathrm{~h}$, and then cleaved caspase- 3 and -9 were analyzed by western blotting. SP600125 and SB202190 treatment significantly attenuated $\mathrm{Ph}$-induced caspase- 3 and -9 activation, as shown in Fig. 7. These findings suggest that activation of JNK1/2 and P38 MAPK may play a crucial upstream role in Ph-mediated caspase activation in A549 cells.

Antitumor activity of Ph on A549 lung tumor xenografts. To further evaluate the tumor-suppressing effect of $\mathrm{Ph}$ in vivo, a model for tumorigenicity of A549 cancer cells in nude mice was established. A549 cells $\left(5 \times 10^{6}\right.$ cells) were injected s.c. 
A

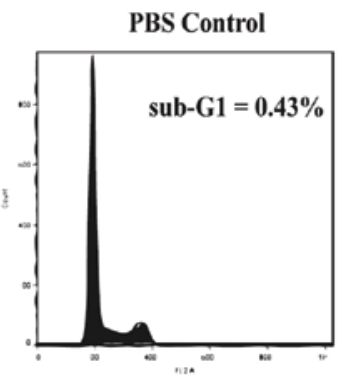

B

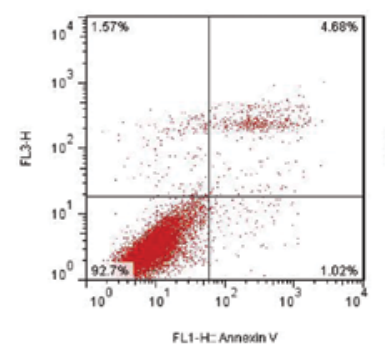

$\operatorname{Ph}(\mathbf{5 0} \mu \mathbf{M})$

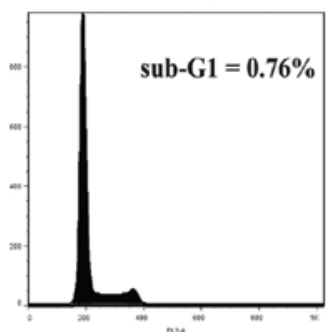

$\operatorname{Ph}(50 \mu \mathrm{M})$

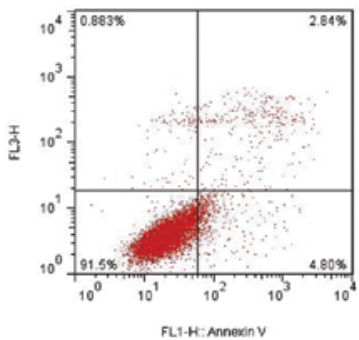

$\operatorname{Ph}(100 \mu \mathrm{M})$

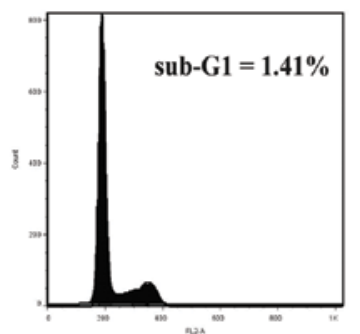

Ph $(100 \mu \mathrm{M})$

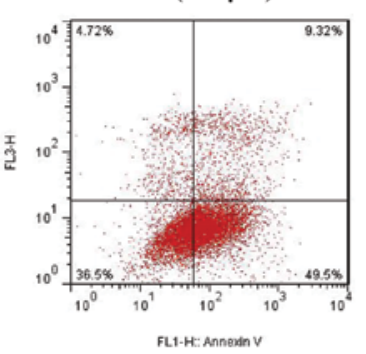

C

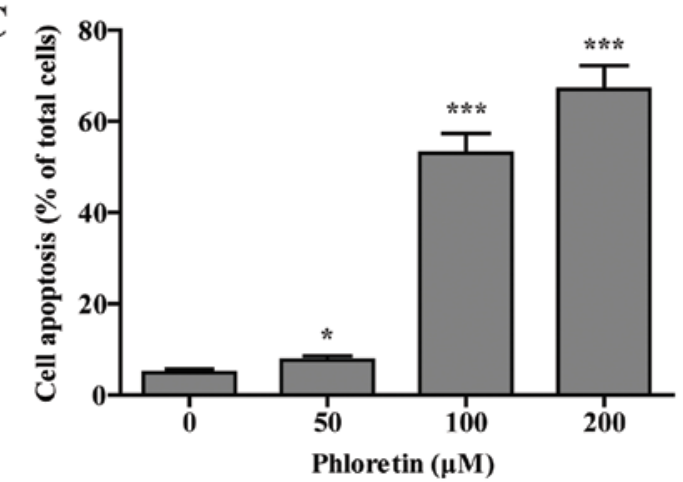

Figure 3. Ph induces cell apoptosis in A549 cells. (A) A549 cells were incubated with indicated concentrations of Ph for $24 \mathrm{~h}$, stained with PI and analyzed for DNA content by flow cytometry. (B) A549 cells were incubated with $\mathrm{Ph}$ for $24 \mathrm{~h}$, harvested, and then subjected to quantitative analysis of cell apoptosis by Annexin V and PI double-stained flow cytometry. (C) The number of apoptotic cells accounts for the total cells of each group after $24 \mathrm{~h} \mathrm{Ph}$ treatment. Data are expressed as mean $\pm \mathrm{SD}, \mathrm{n}=3,{ }^{*} \mathrm{P}<0.05,{ }^{* * *} \mathrm{P}<0.001$.

A

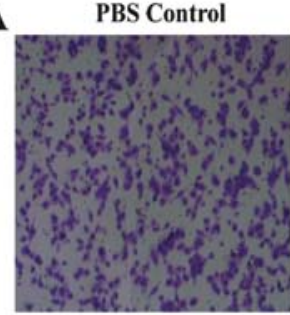

$\mathrm{Ph}(10 \mu \mathrm{M})$

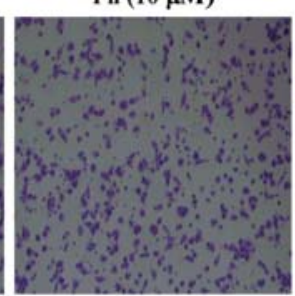

$\mathrm{Ph}(20 \mu \mathrm{M})$

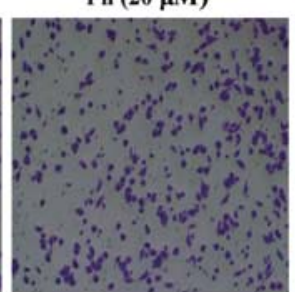

$\mathrm{Ph}(40 \mu \mathrm{M})$

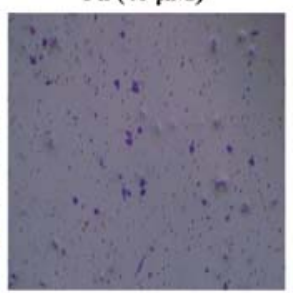

B

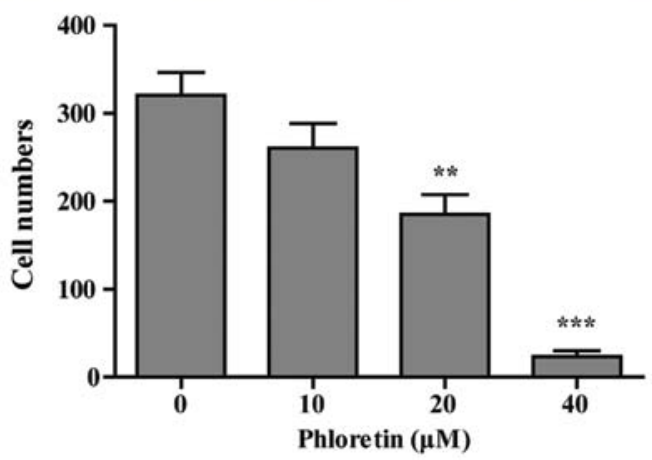

Figure 4. The role of $\mathrm{Ph}$ in Transwell migration of A549 cells. (A) Medium containing 10\% FBS was placed in the lower chamber, and that without FBS was placed in the upper chamber; Ph-treated A549 cells were loaded into the upper migration chamber. (B) Migratory cells in the bottom surface of the membrane were counted. Data are expressed as mean $\pm \mathrm{SD}(\mathrm{n}=3)$. ${ }^{* *} \mathrm{P}<0.005,{ }^{* * *} \mathrm{P}<0.001$. 


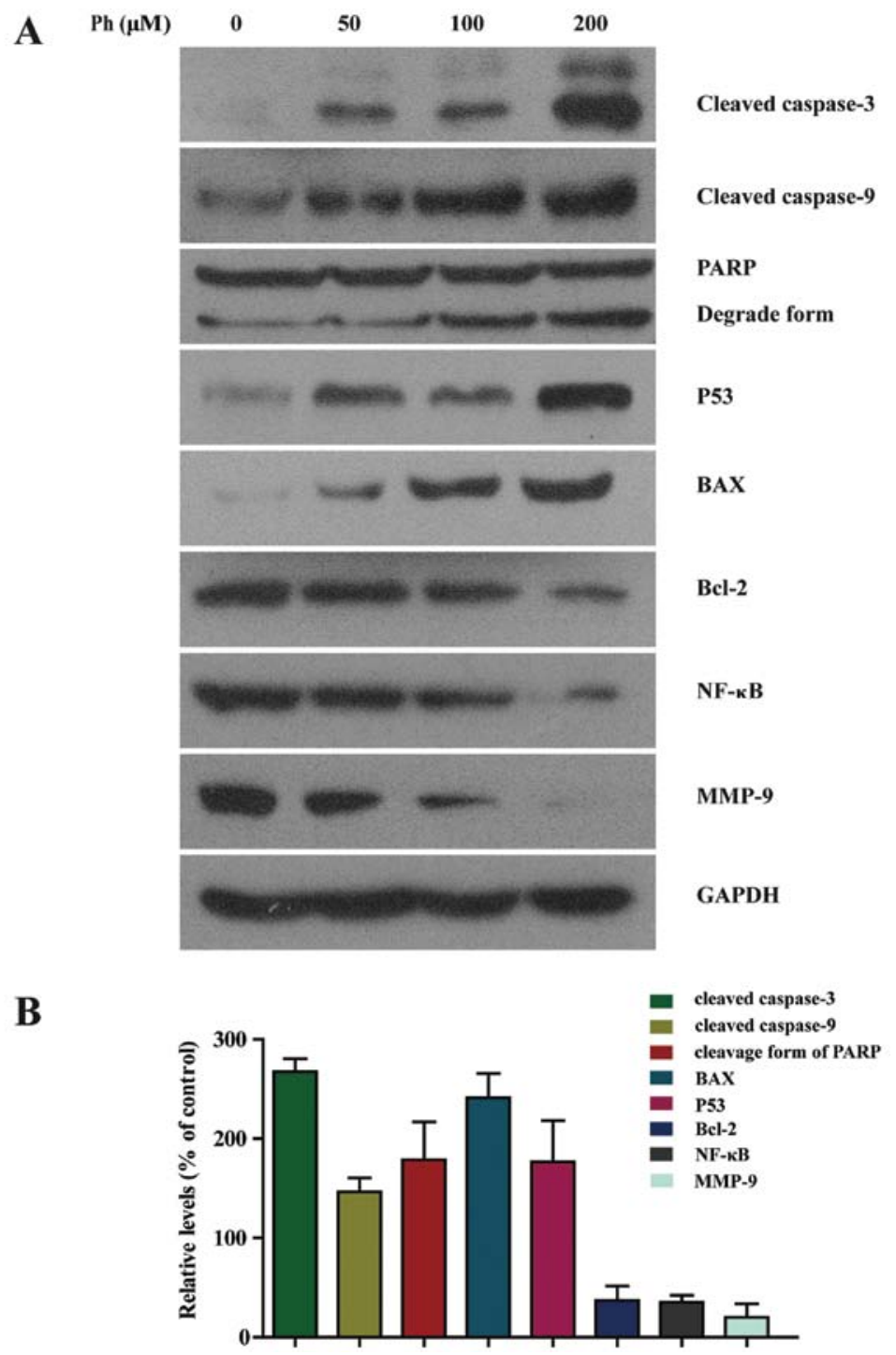

Figure 5. Activation of caspase-3 and -9, PARP, BAX and P53 was increased in Ph-treated A549 cells. (A) A549 cells were treated with 50, 100 and $200 \mu \mathrm{M}$ $\mathrm{Ph}$ for $24 \mathrm{~h}$ and subjected to western blotting with an antibody against cleaved caspase-3 and -9, PARP, BAX, P53, Bcl-2, NF- $\mathrm{B}$ and MMP-9 antibody. (B) Quantitative results of cleaved caspase-3 and -9, PARP, BAX, P53, Bcl-2, NF- $\mathrm{BB}$ and MMP-9 protein levels after $200 \mu \mathrm{M}$ Ph-treated for $24 \mathrm{~h}$, which were adjusted to GAPDH protein level and expressed as multiples of induction beyond each respective control. Data are expressed as mean \pm SD ( $n=3$ ).
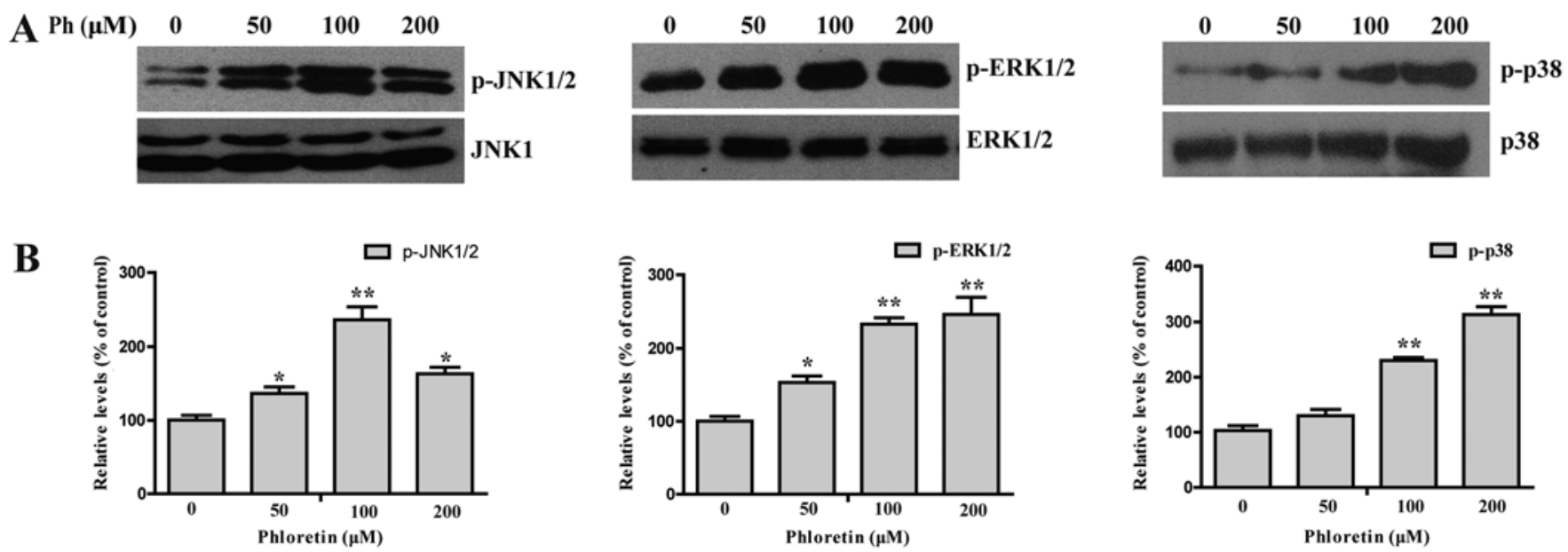

Figure 6. Activation of JNK1/2, ERK1/2 and P38 MAPK was increased in Ph-treated A549 cells. Stimulation of the phosphorylation of ERK, P38 and JNK in A549 cells by $\mathrm{Ph}$. (A) A549 cells were treated with different concentration of $\mathrm{Ph}$ and western blotting were applied for analysis of phosphorylation as described in the Materials and methods. Phosphorylation of ERK, JNK, P38 were significantly elevated with Ph in a concentration-dependent manner. (B) Quantitative results of p-JNK1/2, p-ERK1/2 and p-p38 MAPK protein levels, which were adjusted to GAPDH protein level and expressed as multiples of induction beyond each respective control. Data are expressed as mean $\pm \mathrm{SD}(\mathrm{n}=3)$. ${ }^{*} \mathrm{P}<0.05,{ }^{* *} \mathrm{P}<0.01$. 

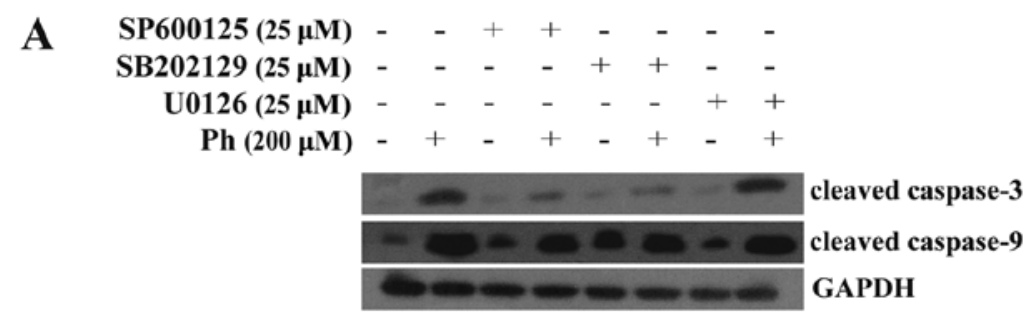

B

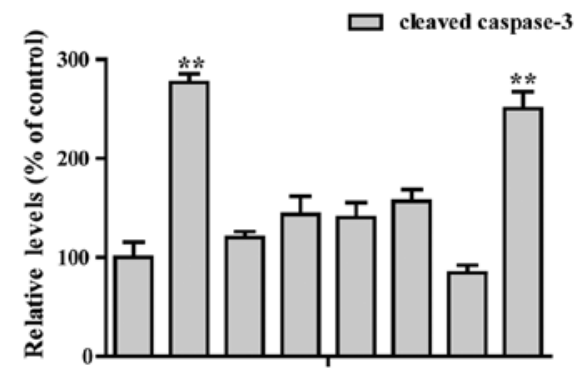

C

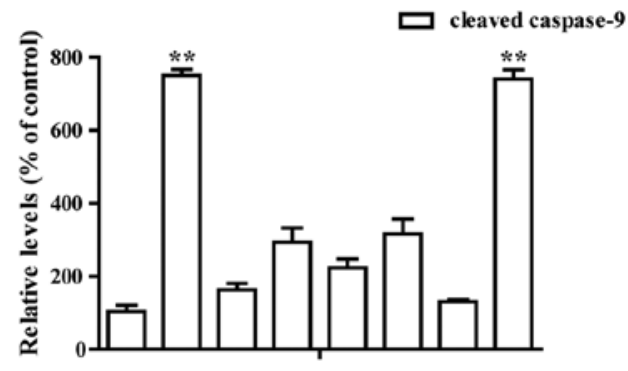

$\begin{array}{rllllllll}\text { SP600125 }(25 \mu M) & - & - & + & + & - & - & - & - \\ \text { SB202129 }(25 \mu M) & - & - & - & - & + & + & - & - \\ \text { U0126 }(25 \mu M) & - & - & - & - & - & - & + & + \\ \text { Ph }(200 \mu M) & - & + & - & + & - & + & - & +\end{array}$

\begin{tabular}{|c|c|c|c|c|c|c|c|}
\hline SP600125 (25 $\mu \mathrm{M})$ & - & - & + & + & - & - & - \\
\hline $\operatorname{SB202129}(25 \mu \mathrm{M})$ & - & - & - & - & + & + & - \\
\hline $\mathrm{U} 0126(25 \mu \mathrm{M})$ & - & - & - & - & - & - & + \\
\hline $\mathrm{Ph}(200 \mu \mathrm{M})$ & - & + & - & + & - & + & - \\
\hline
\end{tabular}

Figure 7. Apoptosis induction by Ph is dependent on the regulation of JNK1/2 and P38 MAPK signaling pathways in A549 cells. Effect of ERK1/2, JNK and p38 MAPK inhibitors on Ph-induced caspase activation. (A) A549 cells were pretreated with $25 \mu$ M U0126, SP600125 or SB202190 for 45 min and then treated with $200 \mu \mathrm{M} \mathrm{Ph}$ for $24 \mathrm{~h}$, respectively. The expression of cleaved caspase-3 and -9 were detected by western blotting. (B and C) Quantitative results of cleaved caspase-3 and -9 protein levels, which were adjusted to the GAPDH protein level. Data are shown with mean $\pm \mathrm{SD}, \mathrm{n}=3,{ }^{* * *} \mathrm{P}<0.01$.

\section{A}

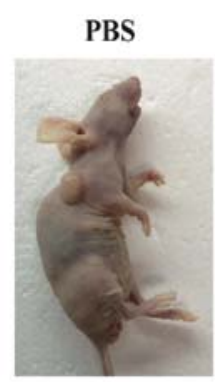

$\mathrm{Ph}(\mathbf{L})$

$\operatorname{Ph}(\mathbf{H})$

B

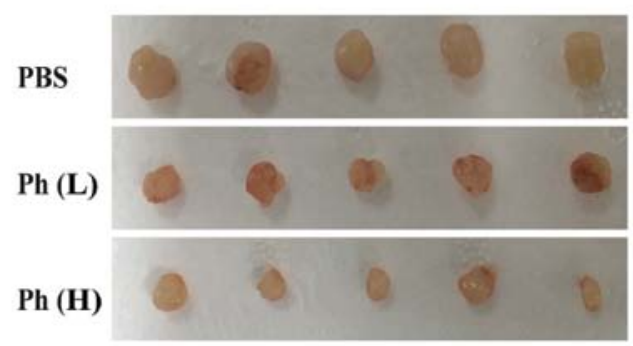

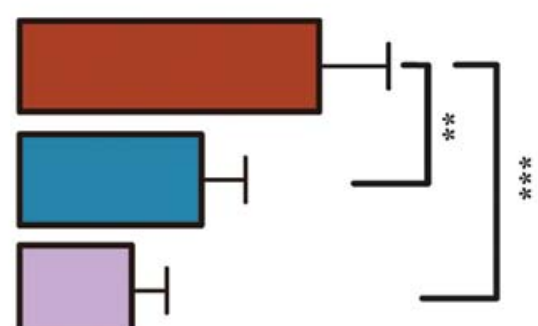

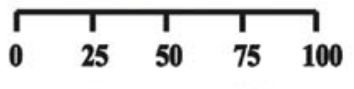

Tumor mass (\%)

Figure 8. Antitumor effect of $\mathrm{Ph}$ in vivo in nude mice. The nude mice were injected with A549 cells and treated with $\mathrm{Ph}$, as described in the Materials and methods. (A) Representative images of Ph-treated nude mice bearing A549 cell xenograft tumors. (B) Weight of the tumors dissected from the nude mice treated with $\mathrm{Ph}$. Ph significantly reduced the tumor weight at the doses of 10 and $20 \mathrm{mg} / \mathrm{kg}$. Data are shown with mean $\pm \mathrm{SD}, \mathrm{n}=5,{ }^{* *} \mathrm{P}<0.01,{ }^{* * * *} \mathrm{P}<0.001$.

into the female nude mice aged 5 weeks and weighing $\sim 20 \mathrm{~g}$. After three days, 15 mice bearing visible tumors were equally randomized to a PBS control, a low-dose $(10 \mathrm{mg} / \mathrm{kg}) \mathrm{Ph}$ group, and a high-dose $(20 \mathrm{mg} / \mathrm{kg}) \mathrm{Ph}$ group. Ph was dispersed in PBS and administered i.p. every two days for three weeks.
After three weeks, mice were sacrificed and tumors were dissected and weighed. Tumor images and mean tumor weight in each group are shown in Fig. 8. As anticipated, the tumor size was decreased significantly in both $\mathrm{Ph}$ groups, compared to that in the control group. The mean tumor mass in low- and 
high-dose Ph groups was $\sim 61$ and $38 \%$ of that in the control group respectively, indicating that $\mathrm{Ph}$ had an inhibitory effect on lung carcinoma xenograft growth in mice.

\section{Discussion}

Lung cancer is the most commonly diagnosed cancer and one of the leading causes of cancer death in males, and was the 4th most commonly diagnosed cancer and the 2 nd leading cause of cancer-related death in females in 2008 worldwide. Lung cancer accounted for $13 \%$ (1.6 million) of the total cases and 18\% (1.4 million) of cancer deaths in $2008(19,20)$. How to enhance antitumor function and expand survival in lung cancer patients has been an open question for decades. Apoptosis (programmed cell death), is not only essential to the development and maintenance of homeostasis during cell growth but plays an important role in the prevention of tumor development $(21,22)$. Natural herbal products are currently studied for their antitumor activities including apoptosis induction and antiproliferative activities (23-25). However, their active components and molecular mechanisms of action are not well understood. $\mathrm{Ph}$ is a natural phenol existing in apples and a variety of vegetables $(26,27)$. $\mathrm{Ph}$ has been previously reported with anticancer effects on breast and hepatocellular cancer and colon cancer cell lines $(5,12,28)$. The present study for the first time demonstrated that $\mathrm{Ph}$ induced apoptosis and inhibit migration of NSCLC A549 cells.

During the apoptotic process, pro-apoptotic Bcl-2 members such as BAX redistribute from the cytosol to mitochondria, resulting in increased membrane permeability. Induction of BAX results in a downstream program of mitochondrial dysfunction and activation of caspases. Due to this event, the released mitochondrial cytochrome participates in this process, leading to caspase- 9 activation and subsequent activation of caspase-3 (29), thus increasing the cleavage form of PARP and inducing A549 cell apoptosis. It was found in the present study that the expression of BAX and fractured PARP protein was increased, the expression of Bcl-2 was decreased, and caspase-3 and -9 were activated in a dose-dependent manner after Ph treatment. In addition, protein MMP-9 was inhibited after $\mathrm{Ph}$ treatment, particularly in the $200 \mu \mathrm{M}$ group. These findings are consistent with the results of cell apoptosis assay and migration assay in the previous experiments. These results proved that $\mathrm{Ph}$ not only induced mitochondrial activationmediated apoptotic cell death but inhibited migration of A549 cells.

Previous studies have suggested that MAPKs can be induced by various compounds and are involved in cell death in NSCLC A549 cells $(30,31)$. The MAPK family includes three kinase members, including c-Jun NH2-terminal protein kinase/stress activated protein kinases (JNK/SAPKs), P38 MAPK, and extracellular signalregulated kinase (ERK). Previous results tempted us to ask whether the tumor-suppressing effect of $\mathrm{Ph}$ relied on the presence of the P38 MAPK signaling system in A549 cells. To answer this question, we further investigated activation of the MAPK family proteins in Ph-treated A549 cells. The results showed that the phosphorylation of ERK1/2, JNK1/2 and P38 MAPK was increased in Ph-treatment A549 cells in a dose-dependent manner with the total protein level remaining steady. However, treatment with JNK1/2 specific inhibitor (SP600125) or the P38 MAPK specific inhibitor (SB202190) effectively inhibited activation of caspase-3 and caspase-9 induced by $\mathrm{Ph}$, whereas U0126 (an ERK1/2 inhibitor) showed no effect on $\mathrm{Ph}$-induced caspase activation. These findings suggest that activation of JNK1/2 and P38 MAPK plays a critical role in Ph-induced apoptosis in NSCLC A549 cells.

\section{Acknowledgements}

This study was supported by the Key Program of the Shanghai Committee of Science and Technology (no. 12JC1410901) and the National Natural Science Funds of China (no. 81402449).

\section{References}

1. Ferlay J, Shin HR, Bray F, Forman D, Mathers C and Parkin DM: Estimates of worldwide burden of cancer in 2008: GLOBOCAN 2008. Int J Cancer 127: 2893-2917, 2010.

2. Shankar S, Ganapathy S, Hingorani SR and Srivastava RK: EGCG inhibits growth, invasion, angiogenesis and metastasis of pancreatic cancer. Front Biosci 13: 440-452, 2008.

3. Boyer J and Liu RH: Apple phytochemicals and their health benefits. Nutr J 3: 5, 2004.

4. Fordham JB, Naqvi AR and Nares S: Leukocyte production of inflammatory mediators is inhibited by the antioxidants phloretin, silymarin, hesperetin, and resveratrol. Mediators Inflamm 2014: 938712, 2014.

5. Zhu SP, Liu G, Wu XT, Chen FX, Liu JQ, Zhou ZH, Zhang JF and Fei SJ: The effect of phloretin on human $\gamma \delta \mathrm{T}$ cells killing colon cancer SW-1116 cells. Int Immunopharmacol 15: 6-14, 2013.

6. Devi MA and Das NP: In vitro effects of natural plant polyphenols on the proliferation of normal and abnormal human lymphocytes and their secretions of interleukin-2. Cancer 69: 191-196, 1993.

7. Nelson JA and Falk RE: The efficacy of phloridzin and phloretin on tumor cell growth. Anticancer Res 13: 2287-2292, 1993.

8. Yang KC, Tsai CY, Wang YJ, Wei PL, Lee CH, Chen JH, Wu CH and Ho YS: Apple polyphenol phloretin potentiates the anticancer actions of paclitaxel through induction of apoptosis in human hep G2 cells. Mol Carcinog 48: 420-431, 2009.

9. Zare Jahromi M, Ranjbarian P and Shiravi S: Cytotoxicity evaluation of Iranian propolis and calcium hydroxide on dental pulp fibroblasts. J Dent Res Dent Clin Dent Prospects 8: 130-133, 2014.

10. Shen J, Song G, An M, Li X, Wu N, Ruan K, Hu J and Hu R: The use of hollow mesoporous silica nanospheres to encapsulate bortezomib and improve efficacy for non-small cell lung cancer therapy. Biomaterials 35: 316-326, 2014.

11. Zuo Y, Yang J, He J, Zhao Y and He Y: An uncoordinated-5 homolog B receptor monoclonal antibody regulates A375 melanoma cell migration. Monoclon Antib Immunodiagn Immunother 33: 280-286, 2014.

12. Wu CH, Ho YS, Tsai CY, Wang YJ, Tseng H, Wei PL, Lee CH, Liu RS and Lin SY: In vitro and in vivo study of phloretin-induced apoptosis in human liver cancer cells involving inhibition of type II glucose transporter. Int J Cancer 124: 2210-2219, 2009.

13. Shao X, Bai N, He K, Ho CT, Yang CS and Sang S: Apple polyphenols, phloretin and phloridzin: New trapping agents of reactive dicarbonyl species. Chem Res Toxicol 21: 2042-2050, 2008.

14. Diefenbach J and Bürkle A: Introduction to poly(ADP-ribose) metabolism. Cell Mol Life Sci 62: 721-730, 2005.

15. Björklund $\mathrm{M}$ and Koivunen E: Gelatinase-mediated migration and invasion of cancer cells. Biochim Biophys Acta 2005: 1755: 37-69, 2005.

16. Dong ZH, Wang DC, Liu TT, Li FH, Liu RL, Wei JW and Zhou CL: The roles of MAPKs in rabbit nucleus pulposus cell apoptosis induced by high osmolality. Eur Rev Med Pharmacol Sci 18: 2835-2845, 2014. 
17. Han R, Liang H, Qin ZH and Liu CY: Crotoxin induces apoptosis and autophagy in human lung carcinoma cells in vitro via activation of the P38 MAPK signaling pathway. Acta Pharmacol Sin 35: 1323-1332, 2014.

18. Palanivel K, Kanimozhi V and Kadalmani B: Verrucarin A alters cell-cycle regulatory proteins and induces apoptosis through reactive oxygen species-dependent P38 MAPK activation in the human breast cancer cell line MCF-7. Tumour Biol 35: 10159-10167, 2014.

19. Jemal A, Bray F, Center MM, Ferlay J, Ward E and Forman D: Global cancer statistics. CA Cancer J Clin 61: 69-90, 2011.

20. Jemal A, Center MM, DeSantis C and Ward EM: Global patterns of cancer incidence and mortality rates and trends. Cancer Epidemiol Biomarkers Prev 19: 1893-1907, 2010.

21. Woodle ES and Kulkarni S: Programmed cell death. Transplantation 66: 681-691, 1998.

22. Bobba A, Amadoro G, La Piana G, Calissano P and Atlante A: Glycolytic enzyme upregulation and numbness of mitochondrial activity characterize the early phase of apoptosis in cerebellar granule cells. Apoptosis 20: 10-28, 2015.

23. Schwingel TE, Klein CP, Nicoletti NF, Dora CL, Hadrich G, Bica CG, Lopes TG, da Silva VD and Morrone FB: Effects of the compounds resveratrol, rutin, quercetin, and quercetin nanoemulsion on oxaliplatin-induced hepatotoxicity and neurotoxicity in mice. Naunyn Schmiedebergs Arch Pharmacol 387: 837-848, 2014

24. Hong JY, Park SH, Min HY, Park HJ and Lee SK: Antiproliferative effects of evodiamine in human lung cancer cells. $\mathrm{J}$ Cancer Prev 19: 7-13, 2014.
25. Zhao B and $\mathrm{Hu} \mathrm{M}$ : Gallic acid reduces cell viability, proliferation, invasion and angiogenesis in human cervical cancer cells. Oncol Lett 6: 1749-1755, 2013.

26. Wang L, Li ZW, Zhang W, Xu R, Gao F, Liu YF and Li YJ: Synthesis, crystal structure, and biological evaluation of a series of phloretin derivatives. Molecules 19: 16447-16457, 2014.

27. Chang WT, Huang WC and Liou CJ: Evaluation of the anti-inflammatory effects of phloretin and phlorizin in lipopolysaccharide-stimulated mouse macrophages. Food Chem 134: 972-979, 2012.

28. Kim MS, Kwon JY, Kang NJ, Lee KW and Lee HJ: Phloretin induces apoptosis in H-Ras MCF10A human breast tumor cells through the activation of p53 via JNK and p38 mitogenactivated protein kinase signaling. Ann N Y Acad Sci 1171: 479-483, 2009

29. Gross A, Jockel J, Wei MC and Korsmeyer SJ: Enforced dimerization of BAX results in its translocation, mitochondrial dysfunction and apoptosis. EMBO J 17: 3878-3885, 1998.

30. Park WH and Kim SH: MAPK inhibitors augment gallic acidinduced A549 lung cancer cell death through the enhancement of glutathione depletion. Oncol Rep 30: 513-519, 2013.

31. Hsiao YC, Kuo WH, Chen PN, Chang HR, Lin TH, Yang WE, Hsieh YS and Chu SC: Flavanone and 2'-OH flavanone inhibit metastasis of lung cancer cells via down-regulation of proteinase activities and MAPK pathway. Chem Biol Interact 167: 193-206, 2007. 